\title{
Crescimento e produção de antúrio cultivado sob diferentes malhas de sombreamento
}

\author{
Growth and yield of anthurium under different shading screens
}

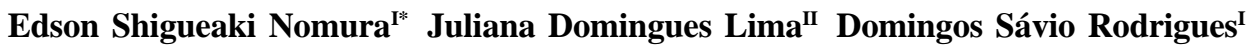 \\ Valéria Augusta Garcia ${ }^{\mathrm{I}}$ Eduardo Jun Fuzitani ${ }^{\mathrm{I}}$ Silvia Helena Modenese-Gorla da Silva ${ }^{\mathrm{II}}$
}

\section{RESUMO}

O uso de malhas ou filmes plásticos de diferente naturezas ou cores pode alterar a qualidade espectral da radiação e, como consequência, o crescimento e a produção de uma cultura vegetal. O objetivo do presente trabalho foi avaliar aspectos do crescimento e da produção de Anthurium andraeanum 'Apalai' sob diferentes malhas de sombreamento. Para tal, mudas micropropagadas foram plantadas em canteiros sob quatro malhas com $70 \%$ de sombreamento (azul, vermelha, preta e termo-refletora). $O$ delineamento experimental foi inteiramente casualizado, com quatro tratamentos e quatro repetições de quatro plantas úteis por parcela. As avaliações foram realizadas durante 12 meses, sendo iniciadas após a produção de hastes florais comercializáveis. A malha preta se sobressaiu em relação às demais, proporcionando a melhor condição para crescimento e produção do antúrio, bem como as maiores dimensões da haste floral, que são consideradas atributos de qualidade para flor de corte.

Palavras-chave: Anthurium andraeanum, flor de corte, florescimento, malhas coloridas, qualidade espectral da radiação.

\section{ABSTRACT}

The use of screen or plastic films of different nature or color can change the quality of spectral radiation, and as consequence the growth and production of a crop. The objective of the present research was to evaluate the growth and yield of Anthurium andraeanum 'Apalai' under different shading screens. For developing such research, micropopageted seedlings were planted in beds under four screens with $70 \%$ shading (blue, red, black and thermo-reflective). The experimental design was completely randomized, with four treatments and four repetitions. The assessments were conducted for 12 months, started after the production of flower stalks marketable. The black screen gave the best results, providing the best conditions for growth and production of anthurium, and the larger dimensions flowers stem, that are considered attributes of quality to cut flower.

Key words: Anthurium andraeanum, cut flower, flowering, colors screens, spectral quality radiation.

\section{INTRODUÇÃO}

O crescimento e o desenvolvimento das plantas podem ser manipulados com o uso de reguladores vegetais. No entanto, isso resulta num incremento no custo de produção. Uma alternativa ao uso de reguladores vegetais é o uso de malhas ou filmes plásticos coloridos que possuem a capacidade de alterar a qualidade espectral da radiação, além de promoverem uma proteção física das plantas.

As respostas de plantas ornamentais às alterações na qualidade da luz incluem aumento da área foliar total em cróton cultivado sob malha de sombreamento vermelha (GAFFNEY, 2004), aumento do comprimento do internódio em crisântemo cultivado sob filme de polietileno azul (OYAERT et al., 1999), aumento da altura e do número de folhas em Dracaena marginata 'Colorama' sob malha de sombreamento vermelha (KOBAYASHI et al., 2006). Outro tipo de

IAgência Paulista de Tecnologia dos Agronegócios (APTA), Pólo Vale do Ribeira, Rod. Régis Bittencourt, BR-116, Km 460, CP 122, Registro, 11900-000, São Paulo, SP, Brasil. E-mail: edsonnomura@apta.sp.gov.br. *Autor para correspondência.

"Campus Experimental de Registro, Universidade Estadual Paulista “Júlio de Mesquita Filho” (UNESP), Registro, SP, Brasil. 
malha de proteção que pode ser utilizada é a termorefletora aluminizada, que altera as propriedades da radiação, aumentando sua reflexão, além de permitir controle de temperatura (ALTAFIN, 2005).

O antúrio (Anthurium andraeanum Lind.) é a principal planta ornamental explorada no Vale do Ribeira, sendo estimada a existência de 1,7 milhões de plantas na região (TOMBOLATO et al., 2002). É uma espécie tropical de grande valor ornamental, comercializada como planta de vaso, para decoração de jardins e interiores, em locais com pouca incidência de radiação. Como flor de corte, é um dos principais produtos de exportação da floricultura brasileira, e sua longevidade após a colheita e arquitetura floral típica têm flexibilidade para harmonizar-se com outras flores, inclusive com as de clima temperado (KIYUNA et al., 2004). A flor comercial, ou haste floral comercializável, é uma inflorescência, composta de pedúnculo, bráctea colorida chamada de espata, e pequena “espiga”, com flores perfeitas, a espádice (HIGAKI et al., 1984).

Antúrio começa a se desenvolver com uma fase vegetativa monopodial, seguida por uma simpodial. A fase monopodial corresponde à fase juvenil e a fase simpodial, à fase reprodutiva, em que uma inflorescência é produzida em cada axila da folha (HIGAKI et al., 1984), mantendo-se a sequência folha e inflorescência, folha, inflorescência durante toda a vida da planta, dependendo das condições ambientais e nutricionais. A fase monopodial representa, portanto, uma despesa para o produtor porque ele mantém sua plantação sem produção.

A necessidade do uso de sombreamento na cultura decorre do fato de o antúrio ser uma planta de sombra no seu habitat natural, que, quando exposta ao excesso de luz, apresenta folhas e inflorescências danificadas, o que pode levar até mesmo à morte da planta. Por isso, recomenda-se o uso de 70 a $80 \%$ de sombreamento (OMAR et al., 2004), o que é normalmente feito pelos produtores de antúrio no Vale do Ribeira com o uso da malha preta.

Assim como todos os fatores que influenciam o desenvolvimento e o crescimento da planta, a resposta à qualidade de luz também depende da espécie em estudo (SCHUERGER et al., 1997; ANTONOPOLOU et al., 2004), portanto, seus efeitos devem ser estudados em função da espécie e da cultivar. Pelo exposto, o objetivo do presente trabalho foi avaliar aspectos do crescimento e da produção de Anthurium andraeanum 'Apalai' sob diferentes malhas de sombreamento.

\section{MATERIAL E MÉTODOS}

O experimento foi realizado no sítio Oriente, localizado no município de Pariquera-Açu, São Paulo (SP). O material vegetal consistiu em plântulas micropropagadas e aclimatadas de Anthurium andraeanum da cultivar 'Apalai', obtidas pelo programa de seleção do Instituto Agronômico de Campinas. O plantio foi realizado em agosto de 2004, em canteiros com 1,2m de largura construídos sob viveiro de $3 \mathrm{~m}$ de pé-direito coberto com diferentes malhas de sombreamento. Na ocasião do plantio, as plântulas apresentavam cerca de $20 \mathrm{~cm}$ de altura. A adubação de plantio seguiu a análise de solo e a recomendação proposta por RAIJ et al. (1997), com a aplicação de $20 \mathrm{~g}$ por planta da formulação NPK 10-10-10 a cada dois meses. Não foi realizada irrigação. Periodicamente, após a colheita das hastes florais, a folha mais velha da planta foi removida, mantendo-se quatro folhas por planta. Foi feita também a distribuição de serragem na superfície dos canteiros para manter a umidade do solo e diminuir a incidência de plantas daninhas.

O delineamento experimental foi inteiramente casualizado, com quatro tratamentos e quatro repetições. Apenas para a variável área foliar total, o delineamento utilizado foi o de parcelas subdivididas no tempo, com seis épocas, ou seja, uma avaliação a cada 60 dias, realizadas durante um ano. As parcelas foram constituídas por quatro plantas úteis, considerando-se, para análise dos dados, a média dessas quatro plantas. Os tratamentos consistiram em quatro malhas de sombreamento: azul (ChromatiNet ${ }^{\circledR}$ Azul 70\%); vermelha (ChromatiNet ${ }^{\circledR}$ Vermelha 70\%); preta (Malha preta 70\%); e termo-refletora (Aluminet $70 \%)$.

As avaliações foram iniciadas após o início da produção de hastes florais comercializáveis, durante 12 meses consecutivos. Para tal, as inflorescências foram colhidas quando a espádice apresentava metade a três quartos das flores verdadeiras abertas, quantidade estimada pela mudança de coloração da base para o ápice da espádice, sendo tomadas as medidas do comprimento do pedúnculo $(\mathrm{cm})$, do comprimento máximo $(\mathrm{cm})$ e da largura máxima da espata $(\mathrm{cm})$ e do comprimento da espádice (cm). Além disso, a cada 60 dias foram determinados as dimensões foliares, comprimento do pecíolo (cm), a largura e o comprimento máximo das folhas (cm) e foi determinada a área foliar total da planta por meio da somatória da área foliar das folhas individuais, estimada pela equação de regressão $A F=0,9672 * C^{*} L$, em que AF é a área foliar $\left(\mathrm{cm}^{2}\right)$, C e L são, respectivamente, o comprimento (cm) e a largura (cm) máximos da folha (MODENESE-

Ciência Rural, v.39, n.5, ago, 2009. 
GORLADA SILVA et al., 2008). Também foram coletados os dados do clima na estação meteorológica da Agência Paulista de Tecnologia dos Agronegócios (APTA), localizada em Pariquera-Açu (Figura 1).

Os dados obtidos foram submetidos à análise de variância, sendo as médias comparadas pelo teste Tukey, a 5\% de probabilidade. Foi realizada também a análise de regressão polinomial para estudar o incremento da área foliar em função das épocas de avaliação, sendo a escolha da regressão baseada na significância do coeficiente de determinação das equações obtidas por meio do teste $t$.

\section{RESULTADOS E DISCUSSÃO}

Plantas cultivadas sob malha preta apresentaram maior comprimento do pecíolo das folhas, quando comparadas com plantas cultivadas nas demais malhas de sombreamento (Tabela 1). O comprimento e a largura máximos médios das folhas obtidos também foram mais altos nas plantas cultivadas sob malha preta (Tabela 1), seguida da malha termo-refletora. Como conseqüuência das dimensões foliares, durante o experimento, plantas cultivadas sob malha preta apresentaram maior desenvolvimento da área foliar total, seguidas por plantas cultivadas sob malha termorefletora (Figura 2). Considerando que a área foliar é uma importante variável para estimativa do crescimento da planta, devido à relação dos órgãos fotossintetizantes com a produção biológica da planta, supõe-se que a malha preta proporcionou a melhor condição para o crescimento do antúrio.
Em cultivo de Aralia sp., Monstera deliciosa, Aspidistra elatior e Asparagus sp., SHAHAK et al. (2002) verificaram atraso no crescimento das plantas sob a malha azul. Todavia, foi observada uma aceleração do crescimento vegetativo sob a malha vermelha, quando comparada com a malha preta. Em Pittosporum variegatum, OREN-SHAMIR et al. (2001) verificaram que a malha azul também proporcionou um desenvolvimento mais lento das plantas. No entanto, malhas de sombreamento vermelha e azul não exerceram efeitos significativos no crescimento de Rhapis excelsa, em relação à malha preta (MEIRELLES et al., 2007).

O incremento da área foliar total em função do tempo, em plantas cultivadas sob malha de sombreamento azul e termo-refletora, foi linear, enquanto que sob malha preta, quadrático e sob malha vermelha foi cúbico, demonstrando maiores oscilações (Figura 2). Uma vez que a área foliar total foi obtida pela soma da área foliar das quatro folhas individuais, seu aumento em função do tempo foi devido exclusivamente ao aumento no tamanho final das folhas e não ao aumento do número de folhas emitido pela planta. Além disso, houve tendência de aumento de área foliar nas plantas, como consequência natural do desenvolvimento das plantas, que, quando juvenis, apresentam folhas menores e, quando adultas, folhas maiores.

No ano de 2006, em Pariquera-Açu (SP), a temperatura mensal média máxima foi de $31,2^{\circ} \mathrm{C}$, e a temperatura mensal média mínima foi de $12,7^{\circ} \mathrm{C}$. Essas temperaturas ocorreram, respectivamente, em fevereiro e agosto (Figura 1). A maior precipitação ocorreu no

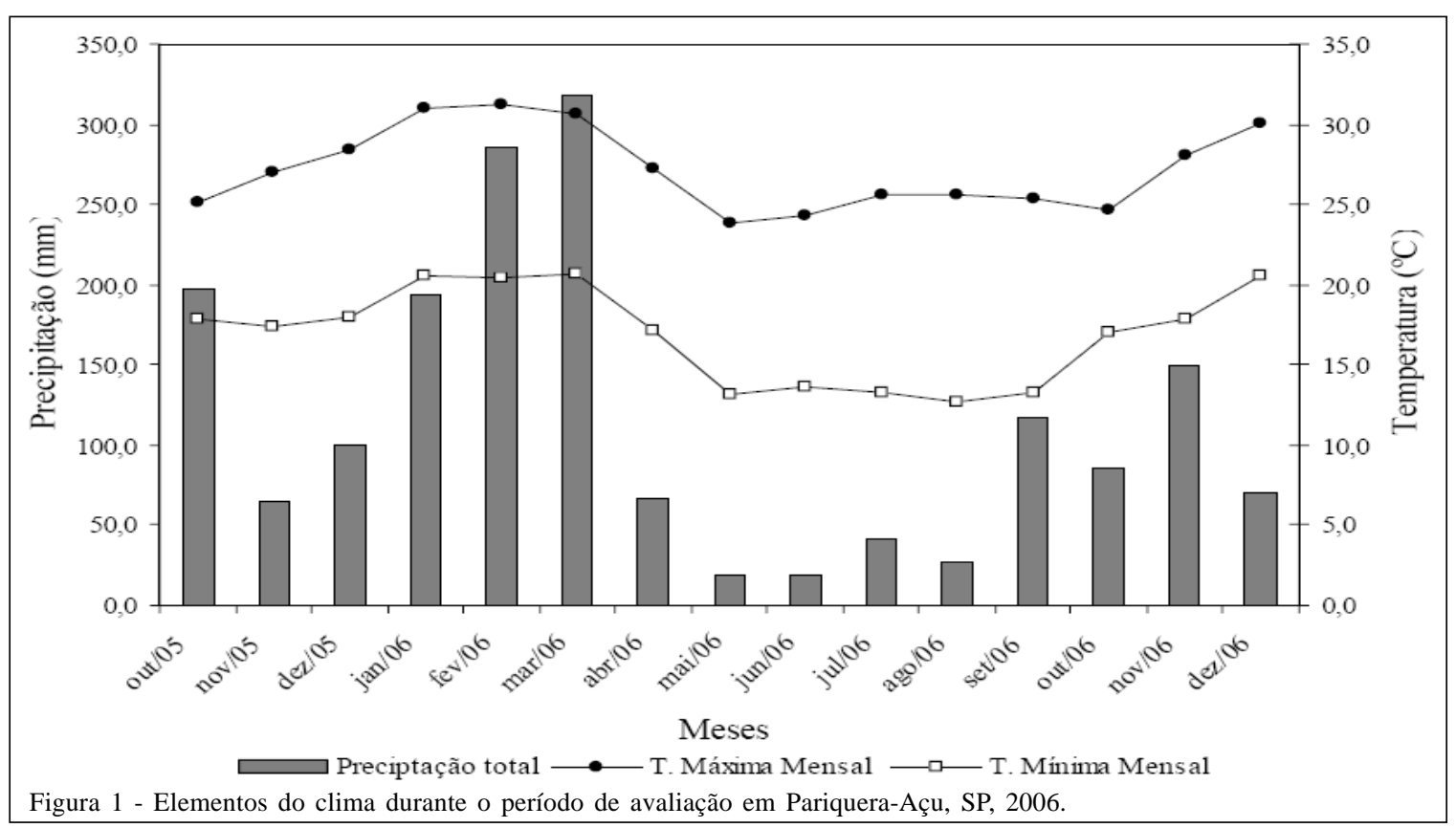

Ciência Rural, v.39, n.5, ago, 2009. 
Tabela 1 - Características morfológicas de folhas de Anthurium andraeanum 'Apalai' cultivadas sob diferentes malhas de sombreamento após o início da produção de hastes comercializá veis: comprimento do pecíolo (CP); comprimento máximo da folha (C) e largura máxima da folha (L). Pariquera-Açu, SP, 2006.

\begin{tabular}{|c|c|c|c|c|}
\hline \multirow{2}{*}{$\begin{array}{l}\text { Malhas } \\
\text { Preta }\end{array}$} & $\mathrm{CP}(\mathrm{cm})$ & $\mathrm{C}(\mathrm{cm})$ & \multicolumn{2}{|c|}{$\mathrm{L}(\mathrm{cm})$} \\
\hline & 28,28 a & 19,82 a & 15,56 & $\mathrm{a}$ \\
\hline Termo-refletora & $22,11 \quad b$ & $16,60 \quad b$ & 13,35 & b \\
\hline Vermelha & 19,71 & 15,93 & 12,45 & bc \\
\hline Azul & 19,11 & 14,54 & 11,31 & C \\
\hline média geral & 22,42 & 16,73 & 13,17 & \\
\hline CV (\%) & 16,15 & 12,57 & 13,85 & \\
\hline DMS & 3,09 & 1,80 & 1,56 & \\
\hline
\end{tabular}

Médias não seguidas da mesma letra na coluna diferem entre si, a 5\% de probabilidade de erro, pelo teste Tukey.

mês de março (318,2mm) e a menor em maio (18,5mm). Pelos resultados apresentados na figura 1 , mesmo nos meses com temperatura e precipitações extremas, houve incremento na área foliar total nas plantas cultivadas sob as malhas de sombreamento preta, termo-refletora e azul, demonstrando que as condições climáticas mais extremas no ciclo anual não impediram o crescimento do tecido foliar (Figura 2). Contudo, sob malha vermelha as plantas apresentaram declínio na área foliar total, no mês de maio, que coincidentemente foi o mês com menor precipitação.

O número médio de hastes florais produzidas planta $^{-1} \mathrm{ano}^{-1}$ foi maior nas malhas de sombreamento preta $(5,94)$ e termo-refletora $(5,86)$ (Tabela 2$)$, não diferindo significativamente entre si. Esses valores, porém, foram mais baixos dos citados por OMAR et al. (2004), que foram de seis a oito hastes florais planta${ }^{1} \mathrm{ano}^{-1}$. Essas diferenças de produtividade podem ser atribuídas às condições climáticas, ao genótipo, à idade das plantas ou aos tratos culturais. Quanto ao tempo para o florescimento, plantas cultivadas sob malhas termo-refletora e preta apresentaram o menor intervalo médio de florescimento, não havendo diferenças significativas entre elas, quando comparadas com plantas cultivadas sob malhas vermelha e azul (Tabela 2). Outro ponto importante é que os diferentes tipos de

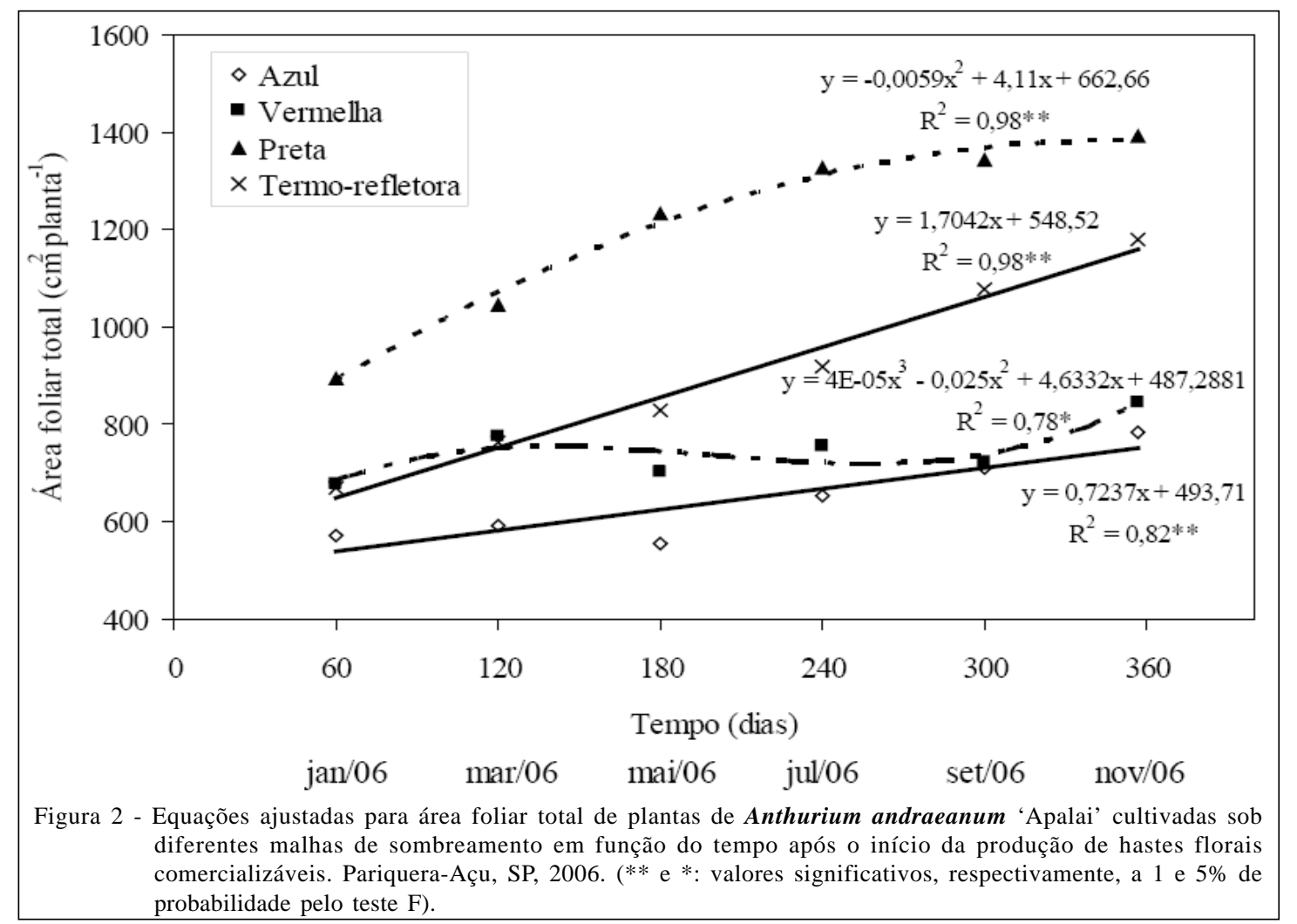

Ciência Rural, v.39, n.5, ago, 2009. 
Tabela 2 - Número médio de hastes florais (NHF) e intervalo de florescimento (IF) em plantas de Anthurium andraeanum 'Apalai' cultivadas sob diferentes malhas de sombreamento após o início da produção de hastes florais comercializáveis. Pariquera-Açu, SP, 2006.

\begin{tabular}{lrrr}
\hline Malhas & \multicolumn{2}{c}{ NHF } & IF (dias) \\
\hline Preta & 5,94 & a & $66,31 \quad$ ab \\
Termo-refletora & 5,86 & a & $65,21 \quad$ a \\
Vermelha & 4,46 & b & $77,85 \quad$ bc \\
Azul & 4,88 & b & $75,50 \quad$ bc \\
média geral & 5,31 & 71,08 & \\
CV (\%) & 16,79 & 13,74 & \\
DMS & 0,23 & 9,57 & \\
\hline
\end{tabular}

Médias não seguidas da mesma letra na coluna diferem entre si, a $5 \%$ de probabilidade de erro pelo teste Tukey.

malha de sombreamento utilizados não afetaram o início da produção de hastes florais, ou seja, não provocaram precocidade no florescimento, o que poderia constituir grande vantagem para o produtor de antúrio. Em Impatiens walleriana e Viola $\mathbf{x}$ witrockiana, cultivadas sob malhas vermelha e azul com sombreamento de $40 \%$ e pleno sol, CUQUEL et al. (2003) verificaram crescimento superior sob malha azul e florescimento precoce sob malha vermelha.

Para o comprimento da haste floral, a malha preta proporcionou os melhores resultados, com uma média de 41,42cm de comprimento (Tabela 3), não havendo diferenças entre os demais tratamentos. Embora o mercado consumidor de antúrio tenha preferência por hastes com comprimento mínimo de $60 \mathrm{~cm}$, segundo TOMBOLATO et al. (2002), essa característica tem sido verificada com pouca frequência nas hastes florais de antúrio.

O maior comprimento da espata foi obtido em plantas cultivadas sob malha preta (Tabela 3). Para largura da espata, o melhor resultado foi obtido para malha preta $(11,88 \mathrm{~cm})$, seguida da termo-refletora
$(10,46 \mathrm{~cm})$ e das malhas vermelha $(9,13 \mathrm{~cm})$ e azul $(8,92 \mathrm{~cm})$, que não diferiram entre si (Tabela 3). Contrariamente, plantas de Anthurium andraeanum 'Lola' cultivadas sob malha vermelha com $70 \%$ de sombreamento apresentaram tamanho da espata superior à espata de plantas cultivadas sob malha preta. No entanto, nessa condição, o número de hastes florais produzidas foi menor (KOBAYASHI et al., 2006). O padrão de classificação adotado no Estado de Pernambuco para diversas cultivares de Anthurium andraeanum, inclusive 'Apalai', baseia-se na largura das espatas, sendo classificadas em pequenas (menor que $8 \mathrm{~cm}$ ), médias (entre 9 e 12cm) e grandes (maior que $12 \mathrm{~cm}$ ) (LOGES et al., 2005). Assim, plantas cultivadas sob malha preta produziram espatas com tamanho que permitiria sua classificação como média.

O maior comprimento da espádice também foi apresentado por plantas cultivadas sob malha preta (Tabela 3), refletindo maior crescimento da inflorescência nesse tipo de malha. Apesar de alguns sistemas internacionais de classificação para comercialização considerarem o tamanho da espádice como critério adicional de qualidade (PAULL \& GOO, 1985), no Brasil, os produtores do Vale do Ribeira não adotam esse critério com precisão. Contudo, descartam hastes florais com espádice muito curta ou curva, conforme recomendado por PAULL (1982).

A malha termo-refletora, além de promover o sombreamento, possui algumas características que diferem da malha preta de sombreamento, tais como a conservação de radiação no ambiente, a reflexão de parte da radiação, a redução da temperatura no verão e o aumento da temperatura no inverno, além de promover a difusão da luz, aumentando a fotossíntese. Em geral, o melhor crescimento e a produção das plantas cultivadas sob malha preta em relação à termo-refletora podem ser atribuídos a um aumento na razão radiação fotossinteticamente ativa e radiação global (RFA/Qg), o que não ocorre sob a malha termo-refletora, conforme

Tabela 3 - Características morfológicas de hastes florais comercializáveis de Anthurium andraeanum 'Apalai' cultivadas sob diferentes malhas de sombreamento: comprimento da haste floral (CHF); comprimento da espata (CE); largura da espata (LE); comprimento da espádice (CESP). Pariquera-Açu, SP, 2006.

\begin{tabular}{|c|c|c|c|c|c|c|c|c|}
\hline \multirow{2}{*}{$\begin{array}{l}\text { Malhas } \\
\text { Preta }\end{array}$} & \multicolumn{2}{|c|}{$\mathrm{CHF}(\mathrm{cm})$} & \multicolumn{2}{|c|}{$\mathrm{CE}(\mathrm{cm})$} & \multicolumn{2}{|c|}{$\mathrm{LE}(\mathrm{cm})$} & \multicolumn{2}{|c|}{$\mathrm{CESP}(\mathrm{cm})$} \\
\hline & 41,42 & $\mathrm{a}$ & 9,30 & $\mathrm{a}$ & 11,88 & $\mathrm{a}$ & 7,27 & $\mathrm{a}$ \\
\hline Termo-refletora & 32,76 & $\mathrm{~b}$ & 8,26 & $\mathrm{~b}$ & 10,46 & $\mathrm{~b}$ & 6,41 & $\mathrm{~b}$ \\
\hline Vermelha & 28,07 & $\mathrm{~b}$ & 7,34 & bc & 9,13 & c & 5,68 & bc \\
\hline Azul & 30,16 & $\mathrm{~b}$ & 7,16 & c & 8,92 & c & 5,57 & C \\
\hline média geral & 33,37 & & 8,04 & & 10,14 & & 6,25 & \\
\hline CV (\%) & 17,45 & & 12,82 & & 13,06 & & 12,81 & \\
\hline DMS & 5,71 & & 1,01 & & 1,30 & & 0,78 & \\
\hline
\end{tabular}

Médias não seguidas da mesma letra na coluna diferem entre si, a 5\% de probabilidade de erro pelo teste Tukey.

Ciência Rural, v.39, n.5, ago, 2009. 
constatado por GUISELINI et al. (2004). Segundo esses autores, a malha termo-refletora, por ser aluminizada, reflete a radiação solar em todos os comprimentos de onda, fazendo com que a proporção de RFA e radiação na faixa do infravermelho (IV), que atinge a superfície no interior do ambiente protegido, mantenha-se. Por outro lado, a malha preta tende a absorver e refletir mais eficientemente comprimentos de onda fora da faixa do visível, promovendo um enriquecimento da RFA no interior do ambiente protegido.

Nas malhas azul e vermelha, a luz transmitida possui um poder de radiação maior (BRAGA, 2006), devido ao fato de a malha azul apresentar pico de transmitância na região do azul-verde (400-540nm), e a malha vermelha apresentar pico de transmitância além de 590nm (OREN-SHAMIR et al., 2001). Essas regiões do espectro são importantes para o processo fotossintético, além de influenciar outros processos na planta. A propriedade mais importante desses tipos de malha é alteração da razão azul:vermelho (A:V), sem alterações significativas na razão vermelho:vermelho distante (V:VD) (GUSSAKOVSKY et al., 2007) e na intensidade da luz transmitida (OREN-SHAMIR et al., 2001). Em outras espécies, a luz vermelha promoveu maior alongamento do caule e florescimento e alterou condutância estomática, enquanto a luz azul influenciou o processo de síntese de pigmentos e enzimas, a abertura e o fechamento estomático, além de processos fotomorfogênicos (SCHURGER et al., 1997).

Neste estudo, provavelmente o menor desenvolvimento da área foliar total de plantas cultivadas sob essas malhas (Figura 2) seja uma consequência da maior transmissividade de radiação na região do espectro absorvida pelos pigmentos fotossintéticos, carotenóides ou clorofilas. Contudo, a maior energia disponível para atividade fotossintética, nas malhas azul e vermelha, provocou mudanças fisiológicas ou microclimáticas negativas no ambiente de cultivo do antúrio, que se refletiram negativamente no crescimento, na produção e na qualidade das hastes florais.

\section{CONCLUSÃO}

Nas condições experimentais estabelecidas, a malha preta com $70 \%$ de sombreamento proporciona a melhor condição de cultivo e produção de hastes florais de Anthurium andraeanum, quando comparada com a malha vermelha, azul e termo-refletora com a mesma intensidade de sombreamento.

\section{REFERÊNCIAS}

ANTONOPOLOU, C. et al. The influence of radiation quality on the in vitro rooting and nutrient concentrations of peach rootstock. Biologia Plantarum, v.48, n.4, p.549-553, 2004.

ALTAFIN, V.L. Estudo da micropropagação, aclimatação e econômico prévio do plantio em campo de Musa spp. 2005. 78f. Tese (Doutorado em Ciências Biológicas) - Curso de Pós-graduação em Ciências Biológicas, Universidade Estadual Paulista, Rio Claro.

BRAGA, F.T. Ambiente de cultivo na propagação in vitro de Crisântemo (Dendranthema grandiflora Tzvelev cv. Rage): características anatômicas e fisiológicas. 2006. 119f. Dissertação (Mestrado em Fisiologia Vegetal) Universidade Federal de Lavras, Lavras.

CUQUEL, F.L. et al. Produção de plantas de jardim em ambiente protegido com sombreamento por malhas que mudam o espectro solar. In: CONGRESSO BRASILEIRO DE FLORICULTURA E PLANTAS ORNAMENTAIS, 14.; CONGRESSO DE CULTURA DE TECIDO DE PLANTAS, 2003, Lavras, MG. Anais.. Lavras: UFLA/FAEPE, 2003.

GAFFNEY, M. ChromatiNet-light spectrum management. Greenhouse Product News, v.14, n.12, p.54, 2004.

GUISELINI, C. et al. Uso de malhas de sombreamento em ambiente protegido II: efeito sobre a radiação solar global e a fotossinteticamente ativa. Revista Brasileira de Agrometeorologia, v.12, n.1, p.1926, 2004

GUSSAKOVSKY, E.E. et al. Color of illumination during growth affects LHCII chiral macroaggregates in pea plant leaves. Journal of Photochemistry and Photobiolog B: Biology, v.86, n.2, p.121-130, 2007

HIGAKI, T. et al. A study of some morphological and anatomical aspects of Anthurium andreanum Lind. Honolulu: University of Hawaii, 1984. 12p. (HITAHR Research Series, 30).

KOBAYASHI, K.D. et al. Effects of photoselective shadecloths on potted Dracaena and Anthurium plants. HortScience, v.41, n.4, p.1053-1054, 2006.

KIYUNA, I. et al. Custo, rentabilidade e avaliação de investimento da produção de antúrio: um estudo de caso. Informações Econômicas, v.34, n.8, p.1324, 2004.

LOGES, V. et al. Colheita, pós-colheita e embalagem de flores tropicais em Pernambuco. Horticultura Brasileira, v.23, n.3, p.699-702, 2005.

MEIRELLES, A.J.A. et al. Influência de diferentes sombreamentos e nutrição foliar no desenvolvimento de mudas de palmeira ráfia Rhapis excelsa (Thunberg) Henry ex. Rehder. Ciência e Agrotecnologia, v.31, n.6, p.18841887, 2007.

MODENESE-GORLA DA SILVA, S.H. et al. Estimativa da área foliar do antúrio com o uso de funções de regressão. Ciência Rural, v.38, n.1, p.243-246, 2008. 
OYAERT, E. et al. Growth of chrysanthemum under coloured plastic films with different light qualities and quantities. Scientia Horticulture, Amsterdam, v.79, p.195-205, 1999.

OMAR, M.H. et al. For market access on anthurium. Kuala Lumpur, Malaysia: Crop Protection \& Plant Quarentine Services Division, Department of Agriculture, 2004. 44p. (Technical Document).

OREN-SHAMIR, M. et al. Colored shade nets can improve the yield and quality of green decorative branches of Pittosporum variegatum. Journal of Horticultural Science and Biotechnology, Ashford, v.76, n.3, p.353-361, 2001.

PAULL, R.E. Anthurium (Anthurium andraeanum) vase life evaluation criteria. HortScience, Alexandria, v.17, n.4, p.606607, 1982.

PAULL, R.E.; GOO, T.T.C. Ethylene and water stress in the senescence of cut anthurium flowers. Journal of the American
Society for Horticultural Science, Alexandria, v.110, n.1, p.84-88, 1985.

RAIJ, B.V. et al. Recomendação de adubação e calagem para o Estado de São Paulo: boletim 100. 2.ed. Campinas: FUNDAG, 1997. 285p.

SHAHAK, Y. et al. Growing Aralia and Monstera under colored shade nets. Olam Poreah July Issure, v.13, n.1, p.60-62, 2002 .

SCHUERGER, A.C. et al. Anatomical features of pepper plants (Capsicum annuum L.) growth under red light emitting diodes supplemented with blue or far-red light. Annals of Botany, London, v.79, n.3, p.273-282, 1997.

TOMBOLATO, A.F.C. et al. O cultivo de antúrio: produção comercial. Campinas: Instituto Agronômico, 2002. 47p. (Série Tecnológica APTA, Boletim Técnico IAC, n.194). 